\title{
Measurement of Fertility Benefits with Low Dose Thyroxine in Sub-fertile women
}

\author{
Upendra Pandit, ${ }^{\mathrm{a}, \mathrm{c}}$ Farhat Banu, ${ }^{\mathrm{b}, \mathrm{c}}$ Ayushma Adhikari ${ }^{\mathrm{b}, \mathrm{c}}$
}

\begin{abstract}
:
Introduction: High prevalence rate of thyroid dysfunction associated infertility is identified by a number of studies in Nepal. Thyroid dysfunction not only affects fertility but is also associated with miscarriage and fetal death. The objective of this study was to measure the fertility rate after low dose Thyroxine, 12.5 microgram, in women with subfertility. Methods: This was a descriptive and observational study done among women visiting infertility and in-vitro fertilization (IVF) center at Nepalgunj Medical College, Nepal. After undergoing baseline investigations for infertility, all women diagnosed with primary or secondary infertility were enrolled in the study. Male factor and tubal factor infertility was excluded. All 136 women who were enrolled in the study received 12.5 microgram of thyroxine supplementation for a period of three months and subsequently followed up until the same time period. Results: Out of 136 women, $83(61.02 \%)$ women achieved pregnancy within three months of supplementation with low dose thyroxine. Among them, $34(40.9 \%)$ women with primary infertility achieved pregnancy within three months. Similarly $14(16.8 \%)$ women with previous miscarriage, $20(24.09 \%)$ women with previous caesarean section within past five years back, and $15(18.07 \%)$ with previous IUFD achieved pregnancy within three months. Conclusion: Low dose thyroxine supplementation would be beneficial and recommended to subfertile women of reproductive age group in the endemic regions of hypothyroidism. Dose adjustment would give extended benefits as soon as pregnancy is achieved.
\end{abstract}

Keywords: fertility agents $\bullet$ infertility $\bullet$ thyroxine

\section{INTRODUCTION:}

Thyroid hormones are necessary to have a healthy reproductive system in women of reproductive age group. Female sex hormones and functioning of reproductive system are

a - Assistant Professor

b - Lecturer

c - Department of Obstetrics and Gynecology

Nepalgunj Medical College Teaching Hospital, Nepal

Corresponding Author:

Dr. Upendra Pandit

e-mail: drupandit@gmail.com

How to cite this article:

Pandit U, Banu F, Adhikari A. Measurement of fertility benefits with low dose thyroxine in sub-fertile women. Journal of Lumbini Medical College. 2016;4(2):80-3. doi: 10.22502/jlmc.v4i2.96. frequently altered due to hypothyroidism or hyperthyroidism which manifests as menstrual disorders like hypomenorrhoea, polymenorrhoea, and oligomenorrhoea. ${ }^{1}$ Hypothyroidism is one of the common public health problems in Nepal due to the location of this country which is far from the sea. Food products available here area poor source of iodine and iron. Nutritional subclinical hypothyroidism and iron deficiency anemia are highly prevalent in this region and about $40-50 \%$ women and children have mild grade anemia. Thyroid hormone is necessary for better iron absorption. ${ }^{2}$ About 5-6\% of women population have hypothyroidism and related illness. There is a strong relationship between thyroid immunity and infertility, miscarriages, and fetal death. Approximately $8-12 \%$ of all pregnancy losses are due to endocrine factors. ${ }^{3}$ Subclinical 
hypothyroidism is more prevalent than overt hypothyroidism. Approximately $80 \%$ of patients with subclinical hypothyroidism have thyroid stimulating hormone $\leq 10 \mathrm{mlU} / \mathrm{L}$. About $11.8 \%$ infertile women have subclinical hypothyroidism. ${ }^{4}$ Secondary amenorrhea due to neuroendocrine cause is approximately $6-10 \%$ in reproductive age group women. Among them, 3-4\% have got infertility. ${ }^{5} \mathrm{~A}$ high incidence of hyperprolactinaemia was found in infertile women and a positive correlation was found between hyperprolactinemia and hypothyroidism. ${ }^{6}$ It is a fact that thyroid hormone deficiency is more common in women with polycystic ovary syndrome. ${ }^{7}$ Subclinical hypothyroidism has a significant association with intrauterine growth restriction as well as low APGAR score at first minute. ${ }^{8}$ Although current evidence does not support that treatment of non-overt thyroid disorders improves maternal and fetal outcomes, further research has been suggested in some studies. ${ }^{9}$

On one hand, levothyroxine treatment is costsaving and it improves the subsequent pregnancy rate in women with spontaneous abortions. On the other hand, only a few studies show that levothyroxine substitution is able to lower the chance of miscarriage and premature delivery. ${ }^{10,11}$ With this background, this study intends to measure the fertility benefits of low dose thyroxine supplementation in cases of subfertility.

\section{METHODS:}

This was a descriptive, observational study comprising a total of 136 cases of primary and secondary sub-fertility visiting infertility and invitro fertilization (IVF) center of Nepalgunj Medical College, Nepalgunj. The cases were enrolled over a period of one year (July 2015 to June 2016). The inclusion criteria for the selection of cases were women who were unable to conceive after more than one year of regular sexual intercourse and diagnosed as cases of sub-fertility. Those who conceived but were unable to sustain pregnancy until term including the history of previous miscarriage, previous intrauterine fetal deaths, and previous operative delivery and unable to conceive for five years of first operative birth were included in the study as cases as sub-fertility.

Cases with male factor and tubal factors infertility with any congenital anomaly of urogenital tract, or any obvious organic pathology were excluded. Those women who had history of thyroid disease, thyroid surgery in the past and those treated with thyroid or anti-thyroid medications were also excluded.

Ethical approval and clearance were taken from ethical review committee of Nepalgunj Medical College Teaching Hospital. Informed consent was taken from all women. Detailed history and personal contact numbers was recorded. Investigations including complete blood count, serology, thyroid stimulating hormone (TSH) test, serum prolactin, hysterosalpingogram, urine routine examination and urine for $\beta$-HCG test were done. All women received tablet thyroxine 12.5 microgram per day in an empty stomach.

The base line TSH profile was categorized as: euthyroid: TSH 0.46 - $4.5 \mathrm{mIU} / \mathrm{ml}$; hypothyroidism: $\mathrm{TSH}>4.5 \mathrm{mIU} / \mathrm{ml}$; hyperthyroidism: $\mathrm{TSH}<0.46$ $\mathrm{mIU} / \mathrm{ml}^{12,13,14}$ Dose adjustment was done as soon as the reports of thyroid functions were received. Thyroxin 12.5 microgram was continued to those who were euthyroid, thyroxine 25 microgram was given for subclinical hypothyroidism and thyroxin 50 microgram for primary hypothyroidism. Antithyroxin was prescribed to those who had hyperthyroidism. All women were followed up for three months and pregnancy rate measured. Microsoft Office Excel 2007 tool was used for statistical analysis.

\section{RESULTS:}

There were 5670 women attending Gynecology outpatient department, Nepalgunj Medical College during the study period. Out of these, 326 were women with sub-fertility giving a hospital incidence of $5.7 \%$. Out of these, 136 women were diagnosed with sub-fertility after basic investigations excluding tubal and male factor infertility. Seventy two women (53\%) had primary infertility; 26 (19\%) had history of previous caesarean section unable to conceive for more than one year of regular sexual intercourse; $21(15 \%)$ had previous miscarriages and 17 (13\%) had previous history of intra-uterine fetal death (IUFD).

Mean age of the study subjects were $26.3 \mathrm{yr}$ $(S D=3.5)$. Among 136 women, 98 (72.05\%) were euthyroid, 37 (27.2\%) had hypothyroidism, and one (0.7\%) had hyperthyroidism.

Eighty-three (61.02\%) women achieved pregnancy within three months of supplementation with low dose thyroxine and folic acid. Among them, 34 (40.9\%) women with primary infertility, 14 (16.8\%) women with previous miscarriage, 20 (24.09\%) women with previous CS within past five 
years, and 15 (18.07\%) women with previous IUFD achieved pregnancy within three months.

\section{DISCUSSION:}

This study revealed that $27.9 \%$ of study population had thyroid dysfunction associated with infertility. Majority of thyroid dysfunction was hypothyroidism (27.2\%); subclinical hypothyroidism being the most common (19.5\%). Similarly, subclinical hypothyroidism was found to be one of the important thyroid dysfunction associated with infertility in previous studies. ${ }^{4,15}$ The overall fertility rate was $61.02 \%$ achieved by low dose thyroxine. Significant achievement was observed in fertility rate ranging from $76.9 \%$ to $88.2 \%$ in secondary sub-fertility including previous operative delivery, previous history of miscarriage, and history of IUFD.

Subclinical hypothyroidism may be associated with ovulatory dysfunction and adverse pregnancy outcome. The high prevalence of hypothyroidism in infertile women shown in this study is also comparable with other similar studies., ${ }^{4,16}$ Higher prevalence of hypothyroidism in our population is due to iodine insufficiency in the diet. ${ }^{17}$ About $13.6 \%$ of population have iodine deficiency in Nepal and the prevalence of hypothyroidism is more in pregnant than in non-pregnant women. ${ }^{18,19}$ Autoimmune thyroiditis may also be contributed to high prevalence rate of hypothyroidism in our population. The diagnosis of which is beyond the scope of this study.

Clinical or subclinical hypothyroidism can cause oligomenorrhea and amenorrhea, polymenorrhea, and menorrhagia in reproductive age group women. High rate of infertility in hypothyroidismalterperipheral estrogenmetabolism.
It is also associated with hyperprolactinemia which ultimately disturbs the release of gonadotrophin releasing hormone $(\mathrm{GnRH})$ secretion and luteinizing hormone (LH) surge. ${ }^{20,21}$

Thyroxine is necessary to achieve maximum fertilization rates and have special roles in oocyte physiology. Serum TSH levels is one of the significant predictors of fertilization failure in women undergoing IVF. ${ }^{22}$ Thyroxine normalizes prolactin levels as well as LH responses to luteinizing hormone releasing hormone (LHRH), normalizes menstrual disturbances, and ultimately enhances the chances of spontaneous conception. ${ }^{23}$ So, it is very important to identify hypothyroidism in infertility.

Low dose thyroxine supplementation is cost effective in those geographical areas where hypothyroidism is endemic. It may be useful even in women without overt hypothyroidism who need extra hormone to regularize their periods as well as to promote the follicular development. It also helps to maintain pregnancy.

\section{CONCLUSION:}

Extended fertility rate was achieved in subfertile women with regular low dose thyroxine supplementation for three months. Low dose thyroxine supplementation is recommended to sub-fertile women of reproductive age group in the endemic regions of hypothyroidism like Nepal. Dose adjustment according to lab test would give extended benefits as soon as pregnancy is achieved.

Conflict of interest: None declared.

Violation of human rights and safety: None.

Fund available: None.

\section{REFERENCES:}

1. Mansourian AR. Female reproduction physiology adversely manipulated by thyroid disorders: a review of literature. Pak J Biol Sci. 2013;16(30):112-20.

2. Ravanbod M, Asadipooya $K$, kalantarhormozi $M$, Nabipour I, Omrani GR. Treatment of iron-deficiency anemia in patients with subclinical hypothyroidism. Am J Med. 2013;126(5):420-4.

3. Sarkar D. Recurrent Pregnancy loss in patients with thyroid dysfunction. Indian J Endocrinnol Metab. 2012;16(S2):S350-1.

4. Rijal B, Shrestha R, Jha B. Association of thyroid disfunction among infertile women visiting infertility centre of Om hospital, Kathmandu, Nepal. Nepal med Coll J. 2011;13(4);247-9.
5. Fourman LT, Fazeli PK. Neuroendocrine causes of amenorrhoea - an update. J Clin Endocrinol Metab. 2015;100(3):812-24.

6. Sharma N, Baliarsingh S, kaushik GG. Biochemical association of hyperprolactinemia with hypothyroidism in infertile women. Clin Lab. 2012;58(7-8):805-10.

7. Andreeva P. Thyroid gland and infertility. Akush Ginekol (Sofiia). 2014;53(7):18-23.

8. Saki F, Dabbagmanesh MH, Ghaemi SZ, Forouhari S, Ranjbar OG, Bakhshayeshkaram M. Thyroid function in pregnancy and its influence on maternal and fetal outcomes. Int J Endocrinol Metab. 2014 Oct 1;12(4): e19378. doi:10.5812/ijem.19378 
9. Barnadi LA, Scoccia B. The effects of maternal thyroid hormone function on early pregnancy. Curr Opin Obstet Gynecol. 2013;25(4):267-73.

10. Bartakova J, Potlukova E, Rogalewicz V, Fait T, Schondorfova D, Telicka Z, et al. Screening for autoimmunine thyroid disordes after spontaneous abortion is cost-saving and improves the subsequent pregnancy rate. BMC Pregnancy Childbirth. 2013;13:217.

11. Medinica S, Nedijkovic N, Stojkovic M, Trbojevic B, Pajovic B. Thyroid dysfunction and thyroid autoimmunity in euthyroid women in achiving fertility. Eur Rev Med Pharmacol Sci. 2015;19(6):977-87.

12. Evered D. Diseases of the Thyroid Gland. Clin Endocrinol Metabol. 1974;3:425-50.

13. Evered DC, Ormston BJ, Smith PA, Hall R, Bird T. Grades of hypothyroidism. Br Med J. 1973;1(5854):657-62.

14. Nicoloff JT, Spencer CA. The use and misuse of the sensitive thyrotropin assays. J Clin Endocrinol Metabol. 1990;71:553-8.

15. Bohnet HG, Fiedler K, Leidenberger FA. Subclinical hypothyroidism and infertility. Lancet. 1981; 2:1278-9.

16. Elahi S, Tasneem A, Nazir I, Nagra SA, Hyder SW. Thyroid dysfunction in infertile women. J Coll Physicians Surg Pakistan. 2007;17:191-4.
17. Pandav CS. IDD in Southeast Asia. Hetzel BS, Pandav CS, (eds). SOS for a billion, the conquest of iodine deficiency disorders. Delhi: Oxford University Press, 1994: 213-31 p.

18. Baral N, Ramprasad C, Lamsal M, Koner BC, Koirala S. Assay of iodine deficiency status in three ecological regions of Nepal by a microdigestion method. Southeast Asian J Trop Med Public Health. 1999;30(3):527-31.

19. Khanal M, Malla S, Sharma V, Gyawali P, Shrestha M, Shrestha R. Assessment of thyroid function in pregnant subjects. J Nepal Assoc Med Lab Sci. 2009;10:39-41.

20. Bulun SE, Adashi EY. The physiology and pathology of the female reproductive axis. Larsen PR. (ed). Williams Textbook of Endocrinology. Philadelphia: WB Saunders, 2003: 587-663 p.

21. Krassas GE. Thyroid disease, menstrual function and fertility. Thyroid International. 2000;1:1-15.

22. Cramer DW, Sluss PM, Powers RD, Mcshane P, Ginsburgs ES, Horenstein MD et al. Serum prolactin and TSH in an in vitro fertilization population: is there a link between fertilization and thyroid function? J Assist Reprod Genet. 2003;20(6):210-5.

23. Redmond GP. Thyroid dysfunction and women's reproductive health. Thyroid. 2004;4(Suppl 1): S5-S15. 